\title{
European salt marshes: ecology and conservation in a changing world
}

\author{
Angus Garbutt ${ }^{1}$ - Alma de Groot $^{2} \cdot$ Chris Smit $^{3} \cdot$ Julien Pétillon $^{4}$
}

Published online: 5 June 2017

(C) Springer Science+Business Media Dordrecht 2017

Keywords Tidal marsh · Conference proceedings · Biogeomorphology $\cdot$ Ecosystem functioning

\section{Introduction}

Saltmarsh habitats have been studied and reported on in the scientific literature for over a century. The earliest papers were given over to descriptive studies of plant species zonation and distribution. As the science of ecology developed, experimental studies set out to understand the physical processes that play such an important part in the formation of salt marshes and their interaction with the biota. As the twentieth century progressed, ecological theory developed into its own branch of science and salt marshes, with their strong environmental gradients and relatively low number species richness, became ideal habitats to test the latest concepts. At the same time, there became greater awareness of the effects of estuarine and coastal zone degradation due to centuries of over-exploitation, habitat modification and pollution resulting in loss of biodiversity

Julien Pétillon

julien.petillon@univ-rennes1.fr

1 Environment Centre Wales, NERC Centre for Ecology \& Hydrology, Deiniol Road, Bangor, Gwynedd LL57 2UW, UK

2 IMARES Wageningen UR, Ankerpark 27, P.O. Box 57, 1780, AB Den Helder, The Netherlands

3 Conservation Ecology group, Groningen Institute for Evolutionary Life Sciences, University of Groningen, Postbox 11103, 9700, CC Groningen, The Netherlands

4 EA Géoarchitecture, Territoires, Urbanisation, Biodiversité, Environnement, Université de Rennes 1, 263 Avenue du Général, Leclerc, 7420535042 Rennes Cedex, CS, France and habitat extent. Studies on habitat management and the restoration of biodiversity and natural processes began to influence policy makers and land managers. Today, there is a global and active science community involved in the descriptive, experimental, applied, theoretical and legislative disciplines of saltmarsh ecology. This special issue brings together some of these areas presented at the Coastal Ecology Workshop, an annual forum for scientists working on saltmarsh related topics throughout Northern Europe.

\section{The evolution of saltmarsh research}

Salt marshes are by their very nature a marginal habitat. They occur on the margins of land and sea and they are marginal in the consciousness of the majority of landlocked populations. Salt marshes have, however, received an enormous amount of attention in the literature, in art and culture, engineering, legislation and policy, and from industry, reflecting their social, scientific and economic importance. They are subject to strong environmental gradients and with relatively low biological diversity make excellent study systems to test ecological theory including biotic/abiotic interactions, herbivory and facilitation, and primary and secondary successions. Salt marshes have been subject to anthropogenic disturbance and modification in addition to responding to the impacts of climate change, making them excellent systems for applied research. They are also subject to international legislation and designations and require systematic monitoring and assessment - e.g. the European Water Framework Directive - which has created a multitude of tools to measure their condition. They are global in their distribution and although salt marshes give way to mangrove habitats on tropical coasts they continue to occur on extensive areas of tropical saline flats (Chapman 1960). Their ubiquitous presence on the soft coasts 
of both hemispheres and the common themes and threats which they are subjected to have led to a large and active community of researchers, public and private sector organisations and policy makers all focussed on the study, exploitation, management and preservation of salt marshes. This variety was reflected in the 22nd Coastal Ecology Workshop held in St Malo, France, October 2014. It is worth reflecting on the history and themes presented at Workshop that serves as a barometer of recent research interest in North-West European saltmarsh science.

In the early 1990s Groningen and Kiel Universities held the first of an annual series of meetings, the 'Coastal Ecology Workshop' on saltmarsh-related research. Since the first meeting the network of participating institutions has grown to include Universities, Government Research Institutes and National Park authorities from across northern Europe and continues to this day. The meeting is intended to be primarily a communication network where $\mathrm{PhD}$ students and early career researchers can network, take advice, develop research ideas, share data and form collaborations to further their own work and advance the coastal science.

The first meeting was held in 1993 in Kiel, Germany and attended by scientists from Kiel and Groningen Universities. The following year Kiel researchers visited the field station (the Herdershut) owned by Groningen on the Wadden Sea island of Schiermonnikoog. Since then the number of participating universities and research institutes has increased to include participants from The Netherlands, Germany, Poland, Belgium, France and the UK. The workshop rotates around Europe each year giving participants the opportunity to visit such iconic salt marsh locations as Mont Saint-Michel (Fr), The Wash (UK), Westerhever (D) and the salt grasslands of the Baltic coast of Germany (Table 1).

The main focus of the CEW are saltmarsh ecosystems. Other coastal ecosystems are presented less (but increasingly) frequently are sand dunes, green beaches, intertidal flats, estuaries and the open sea, and inland saline vegetation. The participants have brought their experience from several centres of saltmarsh research across Europe. The University of Groningen's field station on the Wadden Sea island of Schiermonnikoog (NL) has featured prominently. The island has a chronosequence of marshes spanning 200 years, making it the ideal site for including space-for-time substitution in study designs to test theories on succession, facilitation, grazing and biotic/abiotic interactions. The Hamburger Hallig (D), a small Wadden Sea island surrounded on all sides by saltmarsh, has also featured prominently as a result of its long-term data sets on sedimentation, vegetation, and grazing. From the Scheldt estuary (NL and B) come many studies on Spartina anglica, brackish and freshwater species, the latter also studied in the Elbe estuary (D). The man-made marshes on the Dutch and German mainland coast form a large body of research thanks to their large, long-term databases (Esselink et al. 2009).

The main focus of research in the early 1990s was saltmarsh vegetation, the effect of livestock grazing and soil processes, nutrient pools and Brent (Branta bernicla) and Barnacle (Branta leucopsis) geese. Work on migratory geese were studied along their entire flyway, from their overwintering grounds in the Wadden Sea to the breeding grounds of Northern Russia and included pioneering work of the first GPS-tagged geese. Other species specific work on birds and invertebrates that breed or use saltmarshes during their life cycle have received greater attention in the last few years. At the end of the 1990s, saltmarsh restoration became an important topic as many managed realignment schemes were planned and implemented around Europe. Participants of the $\mathrm{CEW}$ were involved in planning, monitoring, and evaluating several managed realignment sites such as Noord-Friesland Buitendijks (Germany) and Tollesbury (UK, see Garbutt et al. 2006). Reflecting societal and policy interest, climate change and its effect on salt marshes has been a topic since the CEW started. More recently, carbon sequestration and greenhouse-gas emissions from salt marshes were introduced.

As with all semi-natural systems of high conservation value grazing is an important topic to implement management plans and test ecological theory. CEW participants have studied the mechanisms behind grazing often using enclosures, as well as the grazers themselves (hares, geese, and livestock). Terrestrial and marine physical processes driving saltmarsh formation and change and add a level of complexity not seen in other ecosystems. Sedimentation is particularly important and was initially studied as a source of nutrients and elevation for the saltmarsh plants, then as a process in itself and essential for marsh resilience under sea-level rise, and more recently as part of the biogeomorphic interaction that shapes the saltmarsh, Erosion and the interaction between waves and currents and saltmarsh vegetation has been a constant theme.

In recent years the diversity of topics covered during the CEW increased sharply. The backgrounds and home institutes of the participants have broadened, too. Food webs, dunes, seagrass, fish, crustaceans, and benthos were introduced, and the topics have become more interdisciplinary by including for example ecosystem services, coastal defence and socio-economic aspects. The last years, resilience and biogeomorphology have become more important topics. The 2014 meeting was notable for the volume of high quality science presented and interrelated themes (Fig. 1). We have brought these themes and new knowledge together in a special Journal issue by selecting the best papers from the workshop. 
Table 1 Locations, organising institutes and number of participants of the Coastal Ecology Workshop through the years. The programmes of the first four years are lost

\begin{tabular}{|c|c|c|c|}
\hline Year & Location & Organising institute & $\mathrm{N}$ \\
\hline 1993 & Kiel (D) & Kiel University & \\
\hline 1994 & Schiermonnikoog (NL) & University of Groningen & \\
\hline 1995 & Büsum (D) & & \\
\hline 1996 & Haamstede (NL) & NIOO Yerseke & \\
\hline 1997 & Schiermonnikoog (NL) & University of Groningen & $\sim 25$ \\
\hline 1998 & Cuxhaven (D) & Universität Bremen & 33 \\
\hline 1999 & Texel (NL) & Alterra Texel & 31 \\
\hline 2000 & Wilhelmshaven (D) & Forschungsstelle Küste/Universität Oldenburg & 26 \\
\hline 2001 & Monks Wood (UK) & Centre for Ecology \& Hydrology, Monks Wood & 25 \\
\hline 2002 & Greifswald (D) & Ernst-Moritz-Arndt-Universität Greifswald & $\sim 25$ \\
\hline 2004 & Antwerpen (B) & University of Antwerp & 28 \\
\hline 2004 & St. Malo (F) & Université de Rennes 1 & 32 \\
\hline 2005 & Neuwerk (D) & University of Hamburg & 35 \\
\hline 2006 & Wilhelmshaven (D) & University of Oldenburg & 48 \\
\hline 2007 & Schiermonnikoog (NL) & University of Groningen & 47 \\
\hline 2008 & Haamstede (NL) & NIOO-CEME Yerseke & 36 \\
\hline 2009 & Westerhever (D) & Nationalpark Schleswig-Holsteinisches Wattenmeer & $\sim 30$ \\
\hline 2010 & Conwy (UK) & Centre for Ecology \& Hydrology, Bangor & 50 \\
\hline 2011 & Hingene (B) & University of Antwerp & $\sim 50$ \\
\hline 2012 & Lauwersoog (NL) & University of Groningen & 34 \\
\hline 2013 & Spiekeroog (D) & University of Oldenburg & 20 \\
\hline 2014 & St. Malo (F) & Université de Rennes 1 & 47 \\
\hline
\end{tabular}

\section{This special issue}

Physical processes drive saltmarsh distribution and composition and have been the subject of scientific study for at least a century. However, they are highly context dependent and the interplay between sediment properties and supply, geographical setting, hydrology and biology is complex. The paper by de Groot et al. describes the physical characteristics of "island tails', long projections of sediment that form the downdrift sides of the Frisian islands in the North Sea. These island tails are important areas of conservation for the variety of habitats they provide. Large parts of the tails are losing their dynamic nature partly due to human intervention and are in need of regeneration if their conservation interest is to be preserved.
Fig. 1 Schematic view of components of the saltmarsh ecosystem and their linkages that are topics of current research

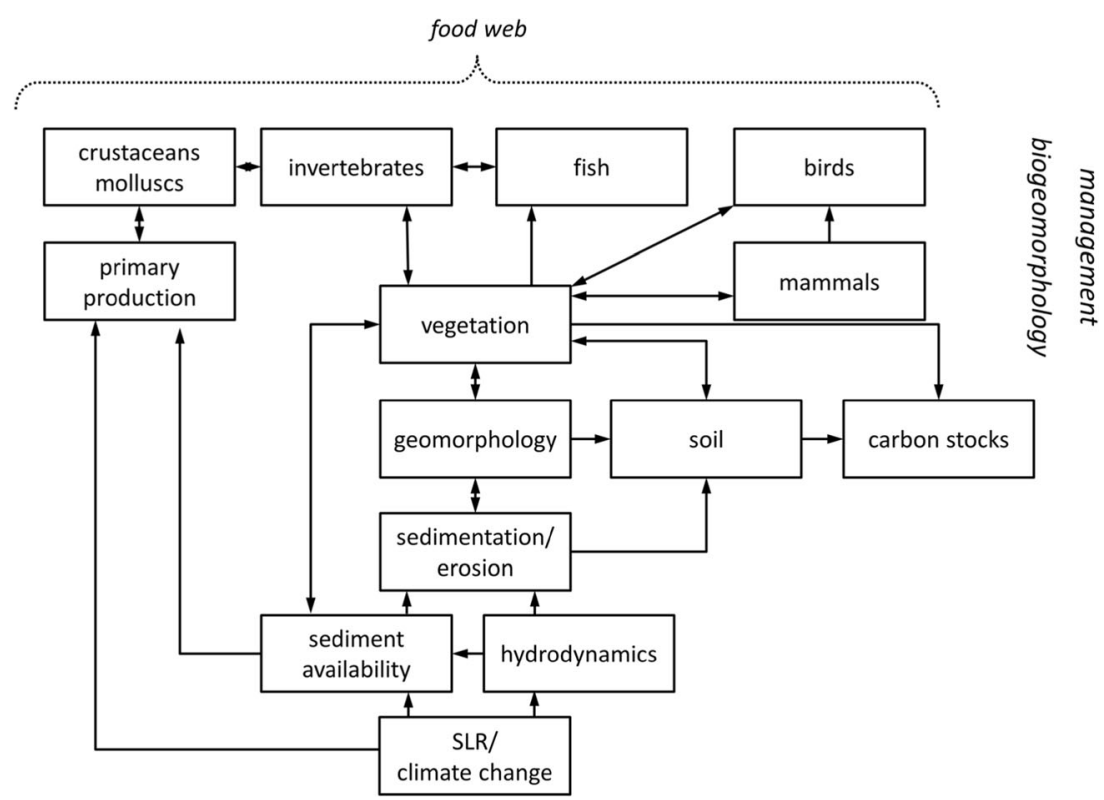


The paper outlines a conceptual model based on existing data, field visits and the literature that aims to provide practical solutions to rejuvenate physical processes and subsequently biological diversity.

Agricultural intensification and the impacts of elevated nutrient loading on semi-natural vegetation has been a subject of intense study across many systems. The critical loads for saltmarshes (i.e. the level above which additional pollutants show harmful effects on the environment) are generally considered too high given that the coastal zone is an open system exposed to inputs from land, sea and air. The consequences of eutrophication have been linked to the spread of Elymus athericus on salt marshes to the detriment of species diversity, a phenomenon that has been recorded across the coasts of mainland Europe. The paper by Valéry et al. highlights the issue and discusses why the grass has only relatively recently started to invade saltmarshes of the Mont Saint-Michel Bay.

It is well recognised that intertidal marshes provide important nursery and rich feeding areas for young fish. During the crucial early-development stage in the life history of fishes, the availability of such habitats plays a significant role in early growth and survival of some species, and consequently an important role in the recruitment process. Much work has been done in North America on fish usage of marshes and restored wetlands in particular. In Northern Europe, the importance of marshes for fishes has only recently begun to be recognized and evidence is limited to a small number of case studies. Joyeux et al. describe the relationship between fishspecies richness in the Bay of Aiguillon, France and habitat diversity. They found an important relationship between plantspecies composition and associated invertebrate community. The unmanaged areas of salt marsh contained the most abundant numbers of invertebrates that provided rich feeding areas for fish. In contrast, areas of saltmarsh that were under management supported less prey for fishes and therefore less fish. This highlights an important point that there are trade-offs to be made in conservation management of saltmarshes that provide multiple benefits such as species diversity, flood protection or carbon storage. Just as saltmarshes provide a multitude of opportunities for research they also provide and multitude of goods and benefits to society and trade-offs have to be made depending on local or national priorities.

Salt marshes in Europe are subject to multiple international and national designations including the Habitats Directive and the Water Framework Directive. The Habitats Directive requires member states to avoid the deterioration of natural habitats within Special Areas of Conservation (SACs) and obliges states to undertake surveillance and reporting of conservation status. The Water Framework Directive (WFD) identifies salt marsh as an important component of the assessment of ecological status of associated water bodies. Enforcement of these directives and monitoring of the condition of the habitat is the duty of the European Governments and their competent authorities. The paper by Haynes et al. describes the development of a national condition monitoring protocol of saltmarsh features and a vegetation survey. The results of the monitoring protocol have provided an insight into the main pressures facing saltmarshes in Scotland and have given a better understanding of the distribution of salt marshes across the country and how they are changing.

Whilst much work has been done, there are still many questions that remain unanswered for European salt marshes such as the assessment of restoration and management practices, quantifying carbon stocks, fish usage and Ecosystems Services, or forecasting resilience to erosion and response to sea level rise. This special issue demonstrates the variety of subjects in saltmarsh ecology, processes, management and policy of this diverse system. Finally, we thank all those that have contributed to the Coastal Ecology Workshop over the last 21 years. In particular, we would like to pay tribute to Professor Jan Bakker who, together with Kathrin Kiehl, initiated the first meeting and was the driving force behind each event until his retirement in 2013.

Acknowledgements We wish to thank Willem van Duin and Steffi Nolte for providing missing workshop programs, and Jan Bakker for proofreading.

\section{References}

Chapman VJ (1960) Salt marshes and salt deserts of the world. Plant science monographs (ed. By N. Polunin). Leonard Hill books limited, London

Esselink P, Petersen J, Arens S, Bakker JP, Bunje J, Dijkema KS, Hecker N, Hellwig AV, Jensen B, Kers B, Körber P, Lammerts EJ, Lüerssen G, Marencic H, Stock M, Veeneklaas RM, Vreeken M, Wolters M (2009) Salt marshes. Thematic report no.8. In Marencic, H. \& de Vlas, J. (Eds). Wadden Sea Quality Status Report 2009. Wadden Sea ecosystems no. 25. Common Wadden Sea secretariat, trilateral monitoring and assessment group, Wilhelmshaven

Garbutt RA, Reading CJ, Wolters M, Gray AJ, Rothery P (2006) Monitoring the development of intertidal habitats on former agricultural land after the managed realignment of coastal defences at Tollesbury, Essex, UK. Mar Pollut Bull 53:155-164 